\title{
Produção de Arroz nas Microrregiões do Rio Grande do Sul \\ Evolução, Especialização e Concentração
}

\author{
Janaina Ottonelli ${ }^{1}$ \\ Taís Cristina Grings ${ }^{2}$
}

http://dx.doi.org/10.21527/2237-6453.2017.40.230-257

\section{Resumo}

0 Brasil é o país com a maior produção de arroz situado fora do continente asiático. Somente 0 Estado do Rio Grande do Sul é responsável por dois terços de toda a produção nacional. Este trabalho questiona se as regiões com maior produção do arroz são especializadas economicamente no produto. Para tanto buscou-se caracterizar a evolução do cultivo desde 1990 até anos recentes, identificar as microrregiões do Rio Grande do Sul especializadas na produção do arroz e verificar 0 grau de concentração da produção ao longo do tempo. A metodologia consistiu na descrição da evolução de produtividade, área colhida e quantidade produzida, no cálculo do Quociente Locacional (QL) para identificação das regiões especializadas e do índice de Gini Locacional (GL) para verificação do grau de concentração da produção de arroz. Ao longo do período analisado houve um aumento no número de regiões especializadas na produção de arroz, mas uma redução na concentração espacial.

Palavras-chave: Arroz. Especialização produtiva. Concentração espacial. Rio Grande do Sul.

\section{RICE PRODUCTION IN THE MICRO-REGIONS OF THE RIO GRANDE DO SUL STATE: EVOLUTION, SPECIALIZATION AND CONCENTRATION}

\section{Abstract}

Brazil is the country with the highest rice production outside Asia. The Brazilian State of Rio Grande do Sul is responsible for two-thirds of all domestic production. This study questions whether the regions with the highest production of rice are economically specialized in the product. Therefore, we

\footnotetext{
1 Doutoranda em Administração pela Universidade Federal de Santa Maria (UFSM). Mestre em Economia pela Universidade Federal do Rio Grande do Norte (UFRN). Graduada em Administração pela Universidade Federal de Santa Maria (UFSM). janainaottonelli@gmail.com

2 Aluna do curso de Administração da Universidade Federal de Santa Maria (UFSM). taisgrings@hotmail.com
} 
aim to characterize the evolution of cultivation from 1990 to recent years, identify the micro-regions of the Rio Grande do Sul State specialized in rice production, and verify the degree of concentration of production over time. The methodology describes the evolution of productivity, harvested area and quantity produced; the measure of the locational quotient $(\mathrm{QL})$ to identify the specialized regions; and the measure of the locational Gini index (GL) to check the degree of concentration of rice production. The results indicate an increase in the number of specialized regions in rice production, but a reduction in the spatial concentration.

Keywords: Rice. Productive specialization. Spatial concentration. Rio Grande do Sul. 
O arroz é um dos cereais mais consumidos no mundo e de grande importância econômica para muitos países da Ásia, África e América Latina. É uma cultura que apresenta capacidade de adaptação a diferentes condições de solo e clima (EMPRESA..., 2010). A produção do cereal no Brasil iniciou-se, segundo Pereira (2002) a partir da chegada dos primeiros colonizadores na Bahia, embora existam registros do cultivo de arroz selvagem pelos índios anteriormente. Nos séculos 17 e 18 o cultivo do arroz sequeiro espalhou-se pelos Estados de São Paulo, Maranhão, Pará e Pernambuco.

No cenário agrícola do Estado do Rio Grande do Sul o arroz começou a surgir a partir de 1824 com a chegada dos alemães em São Leopoldo. Inicialmente, o cultivo do arroz sequeiro servia apenas para o autoconsumo das colônias alemãs recém instaladas e gerava um pequeno excedente comercializável. A produção em lavouras irrigadas surgiu por volta de 1890 às margens do Rio Santa Maria, mediante o uso de bombas para o uso da água do rio na irrigação, e se espalhou pela Depressão Central e litoral da Lagoa dos Patos. A partir do século 20 o arroz foi cultivado em escala comercial no Estado, quando houve aumento do consumo interno e ampliação das áreas destinadas à produção (PEREIRA, 2002).

$\mathrm{Na}$ década de 80 do século 20 até início dos anos 2000 o Brasil configurava-se como importador de arroz dos países vizinhos, como Argentina e Uruguai, para atender à demanda interna, incentivado pelo estabelecimento da união aduaneira do Mercosul, com a redução de barreiras tarifárias e de restrições quantitativas (POERSCHKE; MORAIS, 2014). Por muitos anos esses países foram responsáveis por grande parte do arroz consumido no Brasil devido ao seu potencial de produção, baixo consumo doméstico, baixo custo de produção e de transporte e proximidade física para o fornecimento (OLIVEIRA; STULP, 2011).

O aumento da produtividade média incentivada por aspectos como a abertura comercial em 1990, a estabilização econômica, o controle cambial, a modernização tecnológica e a melhoria da produtividade permitiu ao país tornar-se autossuficiente em arroz na safra 2003/2004 (FOCHEZATTO, 2010; 
MINISTÉRIO DA AGRICULTURA, 2015). Este aumento na produção do arroz está relacionado com o desenvolvimento dos fatores de produção. $\mathrm{O}$ avanço na produtividade do fator terra foi possível com a utilização de sementes modificadas ou melhoradas geneticamente, manejo do solo, adequada adubação e fertilização aliados a boas condições climáticas (ATLAS..., 2015). Os investimentos na formação da mão de obra permitiram o emprego de novas tecnologias de produção (ZAMBERLAN; SONAGLIO, 2011).

Hoje $75 \%$ do arroz produzido no país é do tipo irrigado por inundação, que apresenta maior produtividade do que o sequeiro (EMPRESA..., 2010). O crescimento da produção do arroz resultou na alteração da balança comercial do produto. Segundo dados do Ministério do Desenvolvimento, Indústria e Comércio Exterior (2015), em 2000 o Brasil importou 200,4 mil toneladas de arroz e exportou 73 toneladas, obtendo um saldo negativo na balança comercial. Em 2014 o país importou 36 mil toneladas e exportou mais de 260 mil toneladas, obtendo um saldo positivo de 227 mil toneladas.

A mudança observada com a redução das importações e o aumento das exportações do arroz indica um crescimento da participação do produto no setor agrícola. Para consolidar o país como fornecedor do arroz no mercado externo algumas medidas estão em desenvolvimento. Entidades como Associação Brasileira da Indústria do Arroz (Abiarroz), Agência Brasileira de Promoção de Exportação de Alimentos (Apex-Brasil) e Instituto Rio Grandense do Arroz (Irga) assinaram um convênio de cooperação denominado Programa Brazilian Rice para promover a exportação do cereal brasileiro (INSTITUTO..., 2014).

O Programa Brazilian Rice é resultado de uma demanda da cadeia produtiva e visa à abertura de novos mercados por meio da divulgação do produto e estabelecimento de acordos comerciais para fortalecer o Brasil como um reconhecido produtor, beneficiador e exportador de arroz. Ações como a capacitação de empresas, estudos de novos mercados e melhoria do sistema logístico, principalmente nos portos, estão sendo realizadas para que o país seja reconhecido pela sua qualidade no mercado internacional. 
Outra ação que merece destaque é o programa "Arroz na Bolsa", criado para facilitar a comercialização do arroz em casca gaúcho na Bolsa Brasileira de Mercadorias (2015), por meio de uma plataforma eletrônica de comercialização para ofertas públicas de arroz diretamente de produtores rurais, cooperativas, cerealistas e demais interessados. As medidas praticadas permitem reduzir os impactos das crises com a abertura de novos mercados, garantir uma maior estabilidade dos preços, capacitação e profissionalização comercial das indústrias e qualificar as relações comerciais e internacionais (INSTITUTO..., 2014). O objetivo é garantir a comercialização e cobrir os custos de produção, como arrendamento de terras, fertilizantes, mão de obra, energia elétrica, irrigação, secagem e armazenamento.

Nesse contexto, o Estado do Rio Grande do Sul tem se destacado em termos de produção, na mobilização e organização de entidades para consolidar o arroz como produto de qualidade nacional e internacionalmente. As regiões que cultivam arroz irrigado no Estado são: Fronteira Oeste, Depressão Central, Campanha, Litoral Sul, Planície Costeira Externa da Lagoa dos Patos e Planície Costeira Interna da Lagoa dos Patos. Essas regiões possuem diferenças quanto à topografia, clima, solos, disponibilidade de água para irrigação e tamanho de lavoura, o que determina variações de produção e produtividade média (HOFFMANN et al., 1981; EMPRESA..., 2005).

Dadas as regiões responsáveis pela maior parte da produção do arroz, questiona-se se estas são especializadas economicamente no produto. Por isso, este trabalho busca alcançar três objetivos: i) caracterizar a evolução da produção da cultura no Estado desde 1990 até anos recentes; ii) identificar as microrregiões do Rio Grande do Sul especializadas na produção do arroz e iii) verificar se houve aumento ou redução do grau de concentração da produção do arroz nas regiões investigadas. O que se propõe é conhecer sobre a produção agrícola da cultura do arroz e relacioná-la com aspectos regionais, uma vez que pode se consolidar como produto impulsionador da economia local. 
Para atingir os objetivos propostos, na seção seguinte são apresentadas as principais teorias de desenvolvimento regional que permitem a investigação das regiões especializadas na produção do arroz. Posteriormente, explicitam-se os dados utilizados e métodos empregados para obter os resultados e são descritos e analisados os resultados encontrados. Por fim, são feitas as considerações finais.

\section{Desenvolvimento Regional: teorias e aplicações}

O espaço (território) é resultado das relações sociais e econômicas intermediadas por objetos naturais e artificiais (SANTOS, 1988; LIPIETZ, 1987). O espaço pode ser entendido como uma construção humana que envolve processos de circulação e de troca dependentes do espaço geográfico (BOUDEVILLE, 1969). Desse modo, a região pode ser considerada uma relação social em um segmento particular do território que inclui a localização dos agentes, suas relações e fluxos materiais que realizam, que podem ser definidos a partir de uma relação de domínio territorial particular de uma relação de semelhança (CORAGGIO, 1980).

De acordo com Fochezatto (2010), as teorias de desenvolvimento regional acompanharam as mudanças ocorridas na estrutura da economia e sofreram modificações ao longo do tempo. Essa evolução pode ser dividida em três grandes grupos de teorias, que são: as teorias clássicas de localização, as teorias de economia de aglomeração e as novas abordagens do desenvolvimento regional. Este trabalho tem como foco as duas primeiras teorias, que deram início à investigação sobre o espaço e a formação de aglomerações em razão de determinada produção, conforme exposto a seguir.

\section{Teorias Clássicas da Localização}

As teorias clássicas de localização utilizam o conceito de "livre-mercado" e procuram ressaltar as decisões relativas às firmas que procuram encontrar sua "localização ótima" levando em consideração os custos de 
transporte (CAVALCANTE, 2008). O objetivo principal destas teorias, segundo Fochezatto (2010), é definir modelos de localização da produção, entretanto são teorias estáticas que não levam em consideração a tecnologia.

Os autores que contribuíram para o desenvolvimento das teorias clássicas foram Johann Von Thünen, Alfred Weber, Walter Cristaller, August Lösch e Walter Isard. Von Thünen foi o primeiro autor a dar tratamento formal à localização espacial em economia em seu livro chamado $O$ Estado Isolado, publicado em 1826. Basicamente, o modelo consiste em demonstrar que as terras mais próximas de uma cidade, em que o mercado estaria concentrado, seriam usadas para plantar produtos com maiores custos de transporte. Na medida em que há o distanciamento da cidade a terra seria usada para plantar produtos com custos de transporte menores. Assim sendo, os custos de transporte seriam inversamente proporcionais à distância da cidade (CAVALCANTE, 2008).

Decorridos 80 anos após a publicação de Von Thünen, em 1909, Weber publicou seu livro Teoria da Localização de Indústrias, no qual argumenta que a decisão quanto à localização de atividades industriais decorreria não somente dos custos de transporte, mas também do custo da mão de obra, da posição e do tamanho dos centros de consumo. Como não aceitava a mobilidade espacial da mão de obra, afirmava que se os menores custos dessa mão de obra compensarem os maiores custos de transporte, as indústrias tenderiam a se localizar nas regiões nas quais aquele custo fosse inferior (ALMEIDA, 2013).

Em 1933 Christaller publicou seu livro Teoria dos Lugares Centrais, no qual explica que um determinado lugar central fornece um conjunto de bens e serviços a uma determinada área ao seu redor. Cada lugar central pode ser classificado hierarquicamente conforme a quantidade e diversidade de bens e serviços que pode fornecer para a sua determinada área de influência. Christaller constatou que quanto maior a demanda mínima que 
assegurasse a produção de um bem ou serviço e a distância a ser percorrida para obtê-los, menor seria o número de lugares aptos a oferecer esses bens ou serviços (ALMEIDA, 2013).

Isard publicou o primeiro livro sobre Teorias de Localização em 1956, denominado Location and Space Economy (Teoria da Localização e Economia Espacial). O propósito era oferecer uma síntese na língua inglesa de todas as teorias de localização até então publicadas e mostrar que o desenvolvimento econômico manifesta-se de forma desigual no espaço, que se traduz em disparidades e desigualdades regionais devido aos objetivos e valores dos diferentes grupos sociais nas diversas regiões do mundo. Desse modo, Isard propôs uma linha de pensamento chamada Ciência Regional e a definiu como aquela que "trata do estudo atento e paciente dos problemas sociais nas suas dimensões regionais ou espaciais, empregando diversas combinações de investigação analítica e empírica" (BENKO, 1999, p. 13).

Com o surgimento do termo Ciência Regional, diversos autores dedicaram-se a confrontar o que poderia ter sido obtido dessas teorias e propuseram novos fatores de localização que se adequassem melhor à realidade (CAVALCANTE, 2008). Conforme Almeida (2013), até a década de 1940 as teorias sobre desenvolvimento regional estavam centradas no aspecto da localização das atividades econômicas e seus desdobramentos. A partir da segunda metade do século 20, porém, a análise regional ganha uma abordagem teórica focada nos fatores de aglomeração, que seriam concentrações de indústrias em um mesmo espaço geográfico, o que representava uma série de vantagens para as empresas locais.

\section{Teorias de Economia de Aglomeração}

A partir da década de 1950 surgiram as teorias de desenvolvimento regional que enfatizavam a aglomeração industrial como um fator de localização de novas atividades e de consequente crescimento (BENKO, 1999; MONASTERIO; CAVALCANTE, 2011). Para Almeida (2013), enquanto 
as teorias clássicas consideravam os custos de transporte e mão de obra, as novas teorias passaram a ponderar a complementaridade entre firmas e setores como um fator de localização e de crescimento.

Alfred Marshall foi o pioneiro a abordar o conceito de economias de aglomeração, mostrando que o agrupamento de indústrias gerava benefícios para as pequenas empresas. Marshall defendia que indústrias aglomeradas trabalhando em atividades parecidas geravam vantagens econômicas, as quais surgiam da divisão do trabalho entre empresas do mesmo ramo industrial concentradas em um mesmo espaço geográfico. O conceito de economias externas refere-se aos benefícios que as firmas obtinham ao aglomerarem-se. Estes benefícios eram resultantes da especialização que era obtida da divisão do trabalho, da criação de uma infraestrutura, da troca de informações, da comunicação interna e de uma força de trabalho especializada disponível (FOCHEZATTO, 2010; KELLER, 2008).

Após Marshall, outros autores tentaram compreender o crescimento regional utilizando os fatores de aglomeração. Entre eles destaca-se: Os Pólos de Crescimento, de François Perroux em 1955, A Causação Circular Cumulativa, de Gunnar Myrdal em 1957, e os Efeitos para Trás e Para Frente, de Albert Hirschman em 1958. Cabe salientar que as obras destes autores foram mais influenciadas por Keynes e por Schumpeter do que diretamente por Marshall, especialmente Perroux, que considerava relevante o papel da inovação dinâmica do sistema capitalista (CAVALCANTE, 2008).

Perroux propôs-se a investigar as relações entre as indústrias, denominadas por ele como indústrias motrizes, que têm o poder de aumentar as vendas e compras de outras, e indústrias movidas, que têm suas vendas aumentadas devido à influência das indústrias motrizes. Perroux salienta que o crescimento não é homogêneo no espaço e sim "manifesta-se em pólos de crescimento, com intensidades variáveis, expande-se por diversos canais e com efeitos finais variáveis sobre toda a economia" (PERROUX, 1955, p. 146 apud CAVALCANTE, 2008). 
Myrdal defendeu a intervenção do Estado para conter as forças de mercado, porque estas forças tenderiam a aumentar ainda mais a desigualdade regional. $\mathrm{O}$ autor utiliza o conceito de causação circular cumulativa para explicar a heterogeneidade no desenvolvimento dos países e a desigualdade entre as regiões de um país. Já Hirschman propôs um plano de desenvolvimento por meio de processos de incentivo de modo a mobilizar o maior número de recursos escassos como capital e atividade empreendedora. Discute a questão regional utilizando o conceito de efeitos para frente e para trás. O efeito para frente refere-se à oferta de insumos que tornaria viáveis os setores que se posicionassem a jusante. E o efeito para trás diz respeito às externalidades decorrentes da instalação de indústrias que, ao aumentarem a demanda de insumos no setor a montante permitem uma escala mínima de produção na região (CAVALCANTE, 2008).

Essas teorias formuladas por Perroux, Myrdal e Hirschman deram suporte às políticas públicas e à industrialização que se tornaram forças impulsionadoras do desenvolvimento regional (FOCHEZATTO, 2010). Permitiram também a investigação do contexto regional e a identificação da formação de economias de aglomeração, principalmente relacionadas ao setor industrial. Podem, contudo, existir economias de aglomeração relacionadas a diferentes setores e produtos que impulsionam o desenvolvimento em determinada região devido à coexistência de um certo número de produtores e a relações que se estabelecem entre estes ao longo da cadeia de produção. O relacionamento estabelecido permite o planejamento e a formulação de políticas de desenvolvimento regional.

A questão da aglomeração de atividades pode ser vista como um fator de localização de novas atividades e, portanto, de crescimento e desenvolvimento da região (MONASTERIO; CAVALCANTE, 2011). Os aglomerados geográficos de empresas ou setores, vinculados a uma mesma cadeia produtiva, podem criar oportunidades e novos mercados para atuação diante de um ambiente competitivo e globalizado. Para isso, são necessários recursos estratégicos para permitir o trabalho coletivo e coordenado em busca da 
eficiência, apoiado em aspectos institucionais, trabalhadores qualificados, controle da qualidade dos produtos, padronização da produção do arranjo formação de órgãos técnicos de apoio e de gerenciamento. A concentração geográfica pode gerar o desenvolvimento de vantagens competitivas sustentáveis (SCHMITZ; NADVI, 1999).

A aglomeração de um setor, portanto, seja ele industrial ou agrícola, é um fator impulsionador do desenvolvimento regional, principalmente quando existe trabalho conjunto e organizado entre os produtores. Além de localizar a especialização de uma região em um setor produtivo, verificar o grau da concentração espacial pode indicar se a atividade está concentrada ou distribuída espacialmente.

Esta discussão permite a elaboração de duas hipóteses a serem testadas para o setor produtivo do arroz nas microrregiões do Rio Grande do Sul:

Hipótese A: Existem aglomerações espaciais em relação à produção de arroz e essa identificação pode influenciar o desenvolvimento regional.

Hipótese B: O grau de concentração espacial da produção do arroz ao longo do tempo pode indicar a concentração espacial da atividade no Estado devido às aglomerações.

Para verificar a existência de aglomerações espaciais é possível utilizar técnicas de mensuração como o Quociente Locacional $(Q L)$, o Coeficiente de Especialização $(C E)$ e o Índice de Dessemelhança de Krugman $(S I)$. Neste estudo optou-se pelo Quociente Locacional $(Q L)$, que permite medir o quão especializadas ou distintas as regiões são de algum critério de referência. Esta medida consiste na razão da participação que o setor tem na região e a sua participação do mesmo setor no país. Quando o cociente for maior do que 1 , significa que a região é relativamente mais especializada no setor (MONASTERIO, 2011).

A obtenção do grau de concentração regional normalmente é realizada a partir do cálculo da especialização. Algumas técnicas que permitem essa mensuração são o Coeficiente de Localização $(C L)$, o Índice de Hirschman- 
-Henrfindahl ( $I H H)$ e o Índice de Gini para localização $(G L)$ (MONASTERIO, 2011). Considerou-se o uso do Coeficiente de Gini Locacional (GL) para medir o grau de localização. Este coeficiente é calculado com base na Curva de Lorenz. As regiões são ordenadas pelo seu grau de aglomeração $(Q L)$.

\section{Aglomerações Produtivas Locais: estudos aplicados}

As teorias de aglomeração impulsionaram a investigação da economia no contexto regional por meio do uso instrumentos de mensuração para identificação de regiões especializadas na produção de algum setor ou produto e investigar o grau de concentração regional. Para isso, alguns estudos utilizaram do indicador de especialização Quociente Locacional $(Q L)$, para identificar as regiões especializadas no setor ou produto analisado, e do indicador de Gini Locacional $(G L)$, que mede o grau de concentração de determinado setor ou produto em uma região específica.

As aplicações mais comuns são direcionadas ao setor industrial. Suzigan et al. (2003) buscaram delimitar geograficamente e caracterizar estruturalmente sistemas locais de produção de classes de indústrias no Estado de São Paulo. Os resultados demonstraram elevados valores dos coeficientes $G L$ da indústria de couro e calçados naquele Estado, indicando forte concentração espacial, e o $Q L$ aponta para a existência de três importantes sistemas locais de produção de calçados.

Bitencourt e Guimarães (2012) buscaram identificar e delimitar geograficamente o sistema produtivo local do setor coureiro-calçadista do Estado do Rio Grande do Sul. Os resultados indicaram uma forte concentração espacial das atividades produtivas de curtimento e fabricação de calçados no RS e identificaram as microrregiões especializadas na produção.

Outro exemplo é de Rezende e Diniz (2013), que identificaram aglomerações industriais em regiões de menor expressão econômica, como o Estado de Goiás. Os resultados mostram que dos 24 setores industriais 
analisados, apenas 5 sinalizaram a presença de clusters (aglomerações). Distribuídos entre estes 5 setores estavam presentes 8 clusters industriais, dos quais 5 foram classificados como potenciais e apenas 3 como clusters já consolidados. Tais setores também apresentaram elevada concentração.

Além do setor industrial, também são verificadas aplicações ao setor agropecuário. Um exemplo é o estudo de Marion Filho, Fagundes e Schumacher (2011). Os autores avaliaram a evolução da produtividade, da especialização $(Q L)$ e da concentração $(G L)$ da produção de leite nas microrregiões do Rio Grande do Sul, no período de 1990 a 2009, com base em dados do IBGE e da Fundação de Economia e Estatística do Rio Grande do Sul (FEE). Os resultados mostraram que cresceu a produtividade, a especialização e a concentração na produção de leite no Estado, com a Região Noroeste revelando-se a mais dinâmica. O GL confirmou o aumento da concentração (desigualdade) na produção do leite e o $Q L$ indicou as regiões mais especializadas, com importante expansão da produção de leite em algumas regiões e em outras forte contração.

\section{Materiais e Métodos}

Para analisar a evolução da produção do arroz no Rio Grande do Sul foram usados dados sobre área colhida, quantidade produtiva e rentabilidade média no período de 1991 a 2013. As informações foram levantadas do banco de dados da Fundação de Economia e Estatística (FUNDAÇÃO..., 2015) e utilizadas para a caracterização e cálculo de índice de crescimento ao logo do tempo, medido conforme Hoffmann (2001). Também foram utilizados dados sobre a balança comercial do arroz, de modo a investigar o volume exportado, importado e o saldo do produto no período de 1997 a 2014.

Para identificar as microrregiões especializadas na produção de arroz foram considerados dados da FEE (FUNDAÇÃO..., 2015) para os anos de 1990/1991, 2000 e 2012. Os três períodos considerados permitem verificar se ocorreram mudanças na especialização das microrregiões com relação ao 
produto. Para isso, calculou-se o Quociente Locacional (QL), um indicador de localização ou de especialização, conforme a equação definida por Haddad (1989):

$$
Q L_{i j}=\frac{\left(V P A_{i} / V A A_{i}\right)}{\left(V P A_{j} / V A A_{j}\right)}
$$

em que $V P A_{i}$ é o valor da produção de arroz na microrregião $i ; V A A_{i}$ é o valor adicionado da agropecuária na microrregião $i ; V P A_{j}$ é o valor da produção de arroz no Rio Grande do Sul; $V A A_{j}$ é o valor adicionado da agropecuária no Rio Grande do Sul.

O Quociente Locacional $(Q L)$ é composto por duas medidas relativas. Neste estudo, o $Q L$ informa se a unidade de análise $i$ é especializada na produção de arroz por meio da razão entre a participação do arroz no valor adicionado da agropecuária local e a participação da produção de arroz total do Estado no valor adicionado da agropecuária estadual. Um $Q L \geq 1$ indica que a unidade de análise é especializada.

Alguns autores (PUGA, 2003; SUZIGAN et al., 2003; MARION FILHO; FAGUNDES; SCHUMACHER, 2011) observam que o $Q L$ é preciso ser visto com cautela porque tende a superestimar a especialização em pequenas regiões e a subestimá-la nas grandes. Uma forma de contornar o problema é admitir como especializadas as regiões com $Q L$ mais elevado. Neste estudo, portanto, os resultados da especialização são apresentados em mapas temáticos de modo a indicar as microrregiões especializadas, $Q L \geq 1$, e enfatizando as microrregiões de $Q L \geq 2$ com uma cor mais escura. Assim, ficam destacadas as microrregiões com o dobro de especialização na produção do arroz em relação ao Estado.

Outra medida que permite a investigação regional é o índice de Gini Locacional (GL) proposto por Krugman (1991) e Audretsch e Feldman (1996). Conforme Suzigan et al. (2003), o GL é um indicador do grau de concentração espacial de uma determinada variável em uma certa base geográfica como uma região, Estado ou país. O cálculo do coeficiente de Gini Locacional $(G L)$ é idêntico ao coeficiente de Gini tradicional. Primei- 
ro é preciso ordenar as microrregiões de forma decrescente de Quociente Locacional $(Q L)$. O indicador pode ser encontrado pela equação a seguir, indicada por Hoffmann (2001):

$$
G L=1-\frac{1}{n} \cdot \sum_{i=1}^{n}\left(\theta_{i-1}+\theta_{i}\right)
$$

em que: $n$ é o número de classes calculado pela Regra de Sturges $\left(k=1+3,3(\log n)\right.$, que resultou em 6 classes para 35 microrregiões; $\theta_{i}$ é a participação acumulada porcentual; $\theta_{i-1}+\theta_{i}$ é a participação acumulada percentual mais a classe imediatamente anterior.

O coeficiente $G L$ assume valores de 0 a 1 . Quanto mais espacialmente concentrada for a variável considerada (setor, bem ou serviço) em poucas regiões, mais próximo de 1 estará o índice; e se a variável considerada for uniformemente distribuída, dispersa pelo espaço geográfico, o índice assume valor 0. Conforme Suzigan et al. (2003), o GL é um importante instrumento de análise de concentração e de mapeamento de uma determinada atividade econômica em áreas geográficas.

\section{Resultados e Discussão}

\section{O Arroz no Rio Grande do Sul}

A Figura 1 mostra a evolução da quantidade produzida, da área colhida e do rendimento médio do arroz no Rio Grande do Sul no período de 1991 a 2013 por meio de índices de crescimento, tendo como ano-base 1991. A Tabela 1 apresenta a variação desses índices de crescimento ao longo do tempo, demonstrando o crescimento ou decrescimento dos índices ao longo do período analisado. 
Figura 1 - Índices de crescimento da área colhida, quantidade produzida e rendimento médio do arroz no Rio Grande do Sul de 1991 a 2013, tendo como ano-base 1991

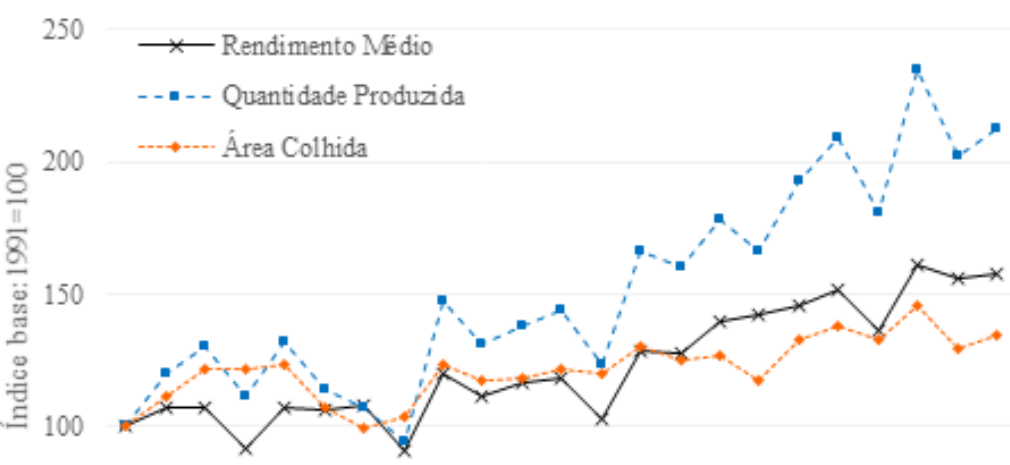

50

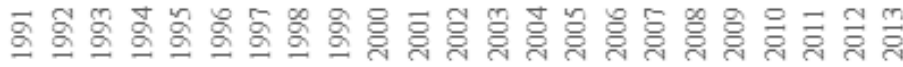

Fonte: Elaborado a partir de dados da FUNDAÇĀO... (2015).

Tabela 1 - Variação percentual dos índices de crescimento da área colhida, quantidade produzida e rendimento médio do arroz no Rio Grande do Sul

\begin{tabular}{|c|c|c|c|c|c|c|c|}
\hline Anos & $\begin{array}{c}\text { Área } \\
\text { colhida } \\
(\%)\end{array}$ & $\begin{array}{c}\text { Quantida- } \\
\text { de produ- } \\
\text { zida }(\%)\end{array}$ & $\begin{array}{c}\text { Rendi- } \\
\text { mento } \\
\text { médio }(\%)\end{array}$ & Anos & $\begin{array}{c}\text { Área } \\
\text { colhida } \\
(\%)\end{array}$ & $\begin{array}{l}\text { Quantida- } \\
\text { de produ- } \\
\text { zida }(\%)\end{array}$ & $\begin{array}{l}\text { Rendimento } \\
\text { médio }(\%)\end{array}$ \\
\hline 1991 & 1 & 1 & 1 & 2003 & 3,09 & 23,30 & 19,61 \\
\hline 1992 & 7,46 & 19,96 & 11,63 & 2004 & 28,13 & 66,38 & 29,85 \\
\hline 1993 & 6,78 & 30,34 & 22,07 & 2005 & 28,07 & 60,21 & 25,10 \\
\hline 1994 & $-8,56$ & 11,06 & 21,45 & 2006 & 39,97 & 78,09 & 27,23 \\
\hline 1995 & 7,54 & 32,25 & 22,98 & 2007 & 42,21 & 66,43 & 17,03 \\
\hline 1996 & 6,55 & 14,36 & 7,33 & 2008 & 45,35 & 92,58 & 32,49 \\
\hline 1997 & 7,71 & 7,19 & $-0,48$ & 2009 & 51,71 & 109,42 & 38,04 \\
\hline 1998 & $-8,86$ & $-5,71$ & 3,46 & 2010 & 36,12 & 80,47 & 32,59 \\
\hline 1999 & 20,09 & 47,79 & 23,07 & 2011 & 61,44 & 134,69 & 45,38 \\
\hline 2000 & 11,35 & 30,75 & 17,43 & 2012 & 56,30 & 101,92 & 29,19 \\
\hline 2001 & 16,81 & 37,98 & 18,12 & 2013 & 57,73 & 112,61 & 34,79 \\
\hline 2002 & 18,01 & 44,02 & 22,04 & & & & \\
\hline
\end{tabular}

Fonte: Elaborado a partir de dados da FUNDAÇÃ̃.... (2015). 
Observa-se que a quantidade produzida apresentou crescimento equivalente ao dobro do período inicial. Conforme dados absolutos da FEE (FUNDAÇÃO..., 2015), a quantidade produzida que era de 3,8 milhões de toneladas em 1991 passou para 8 milhões de toneladas em 2013. O rendimento médio cresceu mais de 57\% em 2013 em relação ao período inicial analisado. O rendimento médio, que era de 4.737 quilos por hectare (kg/ha) em 1991, passou para $7.472 \mathrm{~kg} / \mathrm{ha}$ em 2013 (FUNDAÇÃO..., 2015). A área colhida foi a variável que apresentou o menor crescimento ao longo do tempo, em torno de 37\%. Em 1991 a área colhida de arroz era de mais de 800 mil hectares e passou para mais de 1 milhão de hectares em 2013. Com relação à quantidade produzida e rendimento médio, verifica-se quedas do crescimento nos anos de 1994, 1998, 2003 e 2010 (FUNDAÇÃO..., 2015).

O crescimento da quantidade produzida e rendimento médio influenciou na balança comercial do arroz no Estado. A Figura 2 apresenta a quantidade de exportações de arroz, importações e o saldo da balança comercial, ocorridos nos anos de 1997 a 2014. Percebe-se um elevado nível de importações em comparação ao de exportações de 1997 até 2004, com destaque para os anos de 1998 e 2003 . A partir de 2005 observa-se uma mudança na balança comercial do arroz, quando o saldo passa a ser positivo com o crescente volume de exportações e a redução do volume de importações. 
Figura 2 - Balança comercial do arroz em casca no Rio Grande do Sul, 1997 a 2014

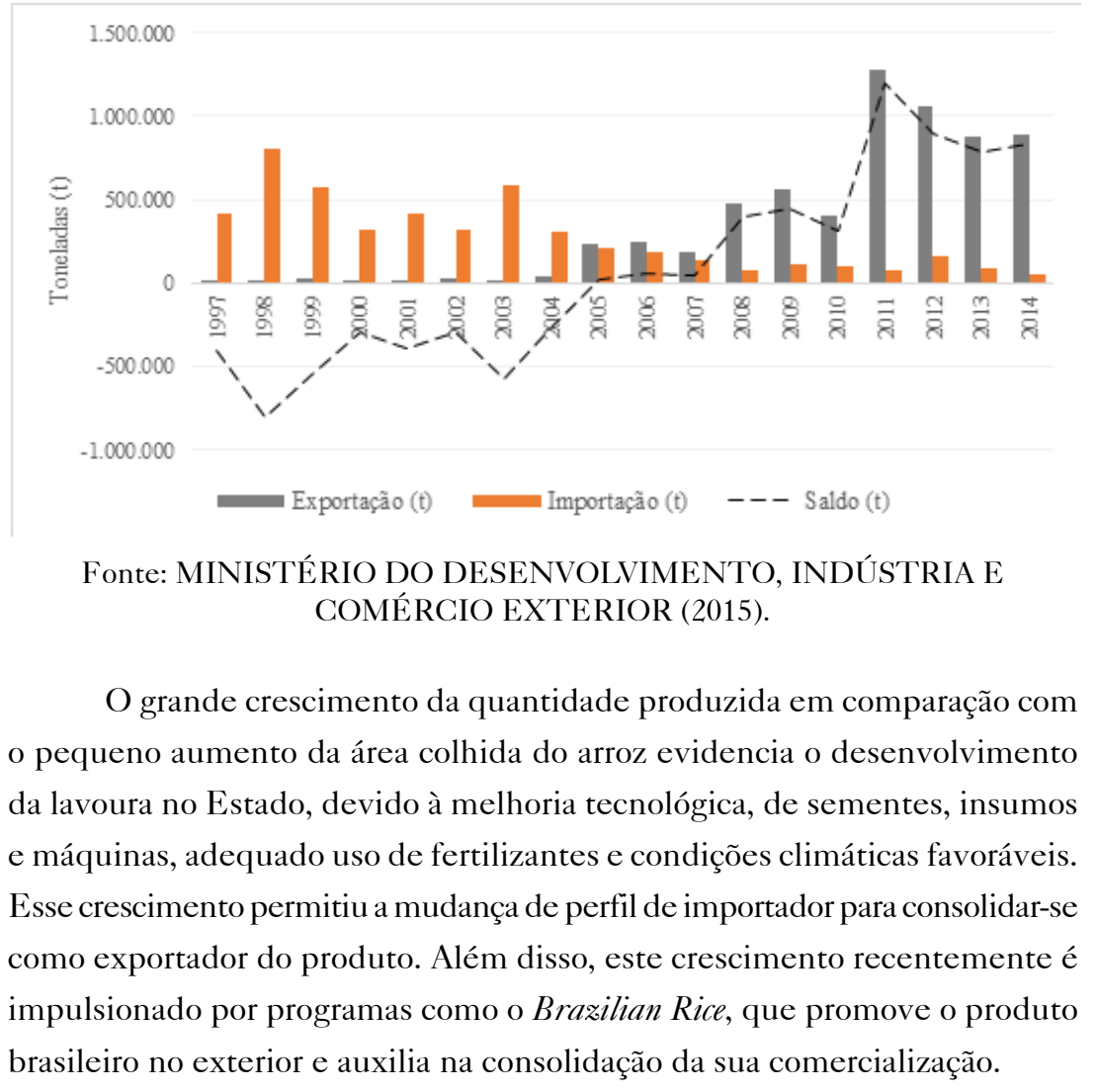

\section{Especialização e Concentração na Produção de Arroz}

A Figura 3 mostra as microrregiões especializadas de arroz no Estado nos anos de 1990 e 1991. Optou-se por utilizar os dados disponíveis do valor adicionado bruto da agricultura do ano de 1990 e os dados do valor da produção de arroz para o ano de 1991 para tornar possível a análise da evolução da especialização econômica das microrregiões com relação ao produto no maior período possível de dados disponíveis. 
Admitindo-se um índice de Quociente Locacional $(Q L)$ igual ou maior que 1, temos as seguintes microrregiões especializadas: Santa Maria, Restinga Seca, Cachoeira do Sul, Pelotas e Porto Alegre. Para um índice $Q L$ igual ou maior que 2, que indica maior índice de especialização, tem-se as microrregiões especializadas: Campanha Ocidental, Campanha Central, Campanha Meridional, Jaguarão, Litoral Lagunar, Camaquã e Osório.

Figura 3 - Microrregiões especializadas na cultura do arroz em 1990/1991

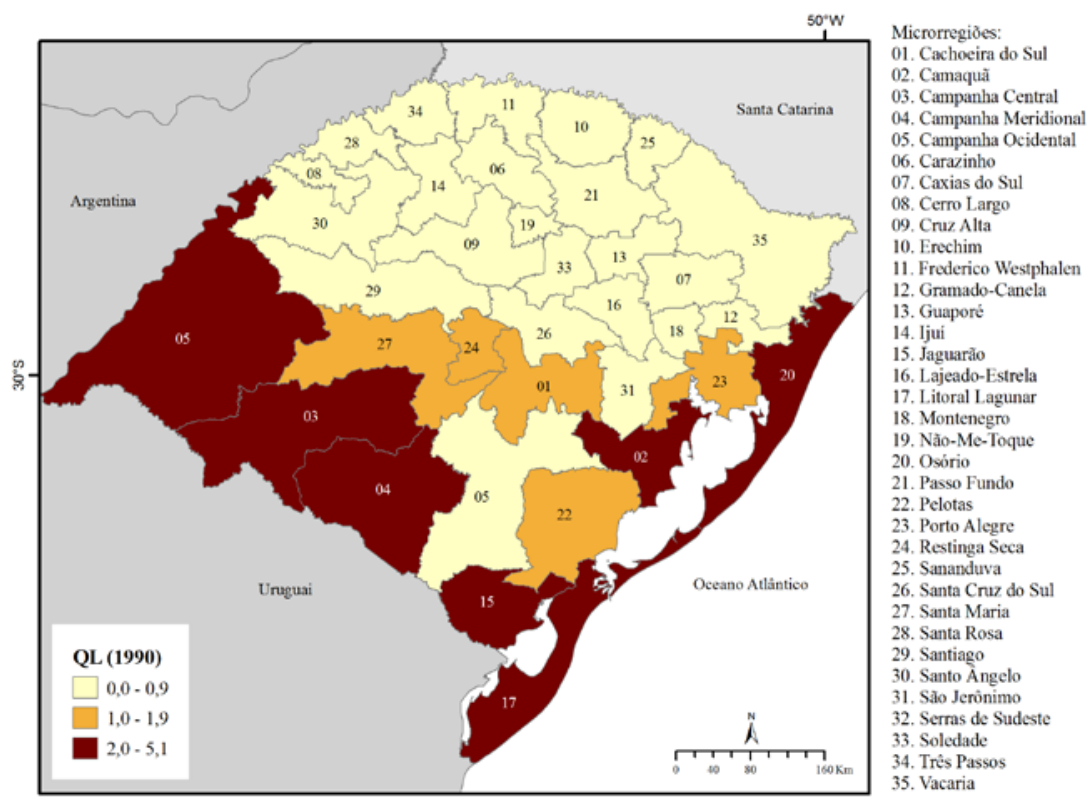

Fonte: Elaborado pelas autoras.

A Figura 4 mostra as microrregiões especializadas em arroz no ano de 2000. Quando comparada com a Figura 3, observa-se que as microrregiões de Santa Maria e Restinga Sêca apresentaram um aumento no índice de especialização $Q L$. A microrregião de São Jerônimo passou a ser especializada na produção de arroz com om QL maior do que 1. 
Figura 4 - Microrregiões especializadas na cultura do arroz em 2000

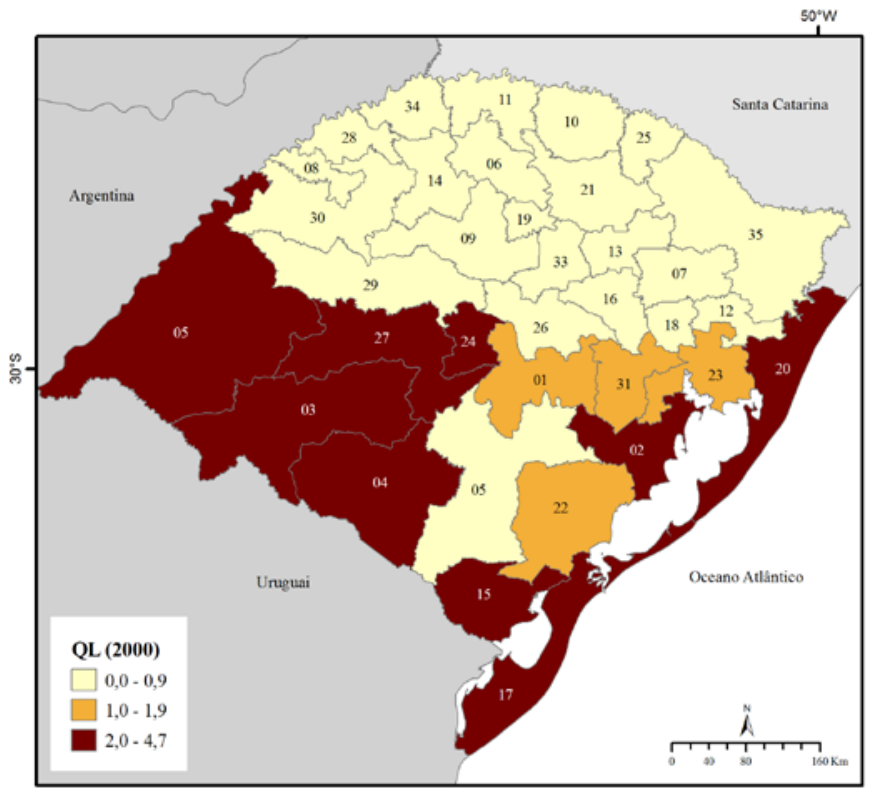

Microrregiồes:

01. Cachoeira do Sul

02. Camaquà

03. Campanha Central

04. Campanha Meridional

05. Campanha Ocidental

06. Carazinho

07. Caxias do Sul

08. Cerro Largo

09. Cruz Alta

10. Erechim

11. Frederico Westphalen

12. Gramado-Canela

13. Guaporé

14. Jjú

15. Jaguarã̀o

16. Lajeado-Estrela

17. Litoral Lagunar

18. Montenegro

19. Nåo-Me-Toque

20. Osório

21. Passo Fundo

22. Pelotas

23. Porto Alegre

24. Restinga Seca

25. Sananduva

26. Santa Cruz do Sul

27. Santa Maria

28. Santa Rosa

29. Santiago

30. Santo Angelo

31. São Jerônimo

32. Serras de Sudeste

33. Soledade

34. Três Passos

35. Vacaria

Fonte: Elaborado pelas autoras.

A Figura 5 apresenta as microrregiões especializadas em arroz no Estado para o ano de 2012. Verifica-se uma mudança de 2000 para 2012: algumas microrregiões que apresentavam índice de especialização QL igual ou superior a 1 tornaram-se também especializadas para um QL igual ou superior a 2, que são as microrregiões de Cachoeira do Sul e Porto Alegre.

As mudanças verificadas ao longo do período considerado indicam um crescimento do número de microrregiões especializadas economicamente no produto. Conforme a Tabela 2, que apresenta os valores do índice $Q L$ para as microrregiões especializadas, verifica-se que as microrregiões que apresentaram maior crescimento da especialização foram Campanha Ocidental, Osório, Porto Alegre e Restinga Seca. As microrregiões que apresentaram redução no índice de especialização foram Jaguarão e Litoral Lagunar. 
Figura 5 - Microrregiões especializadas na cultura do arroz em 2012

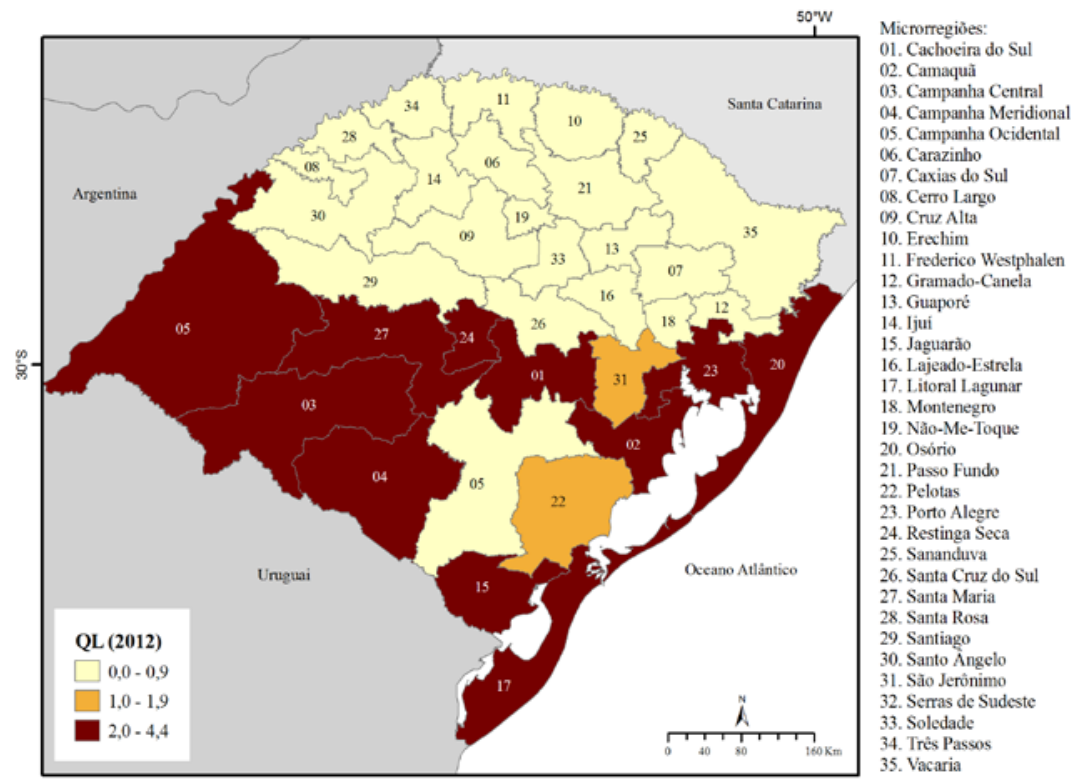

Fonte: Elaborado pelas autoras.

Tabela 2 - Microrregiões especializadas na cultura do arroz

\begin{tabular}{lccc}
\hline \multicolumn{1}{c}{ Microrregiões } & QL 1990/1991 & QL 2000 & QL 2012 \\
\hline 1. Cachoeira do Sul & 1,86 & 1,89 & 2,01 \\
2. Camaquã & 3,62 & 3,03 & 3,35 \\
3. Campanha Central & 2,05 & 2,66 & 2,09 \\
4. Campanha Meridional & 2,26 & 2,90 & 1,99 \\
5. Campanha Ocidental & 3,99 & 4,33 & 4,41 \\
15. Jaguarão & 5,14 & 4,63 & 3,80 \\
17. Litoral Lagunar & 4,62 & 4,67 & 4,05 \\
20. Osório & 3,72 & 3,75 & 4,00 \\
22. Pelotas & 1,21 & 1,29 & 1,13 \\
23. Porto Alegre & 1,85 & 1,87 & 2,55 \\
24. Restinga Seca & 1,64 & 2,17 & 3,05 \\
27. Santa Maria & 1,76 & 2,33 & 2,01 \\
31. São Jerônimo & 0,92 & 1,41 & 1,40 \\
\hline
\end{tabular}

Fonte: Elaborado pelas autoras. 
A Tabela 3 apresenta os índices de crescimento da área colhida, quantidade produzida e rendimento médio do arroz referente às microrregiões especializadas no produto para os anos de 1991, 2000 e 2012. As microrregiões que apresentaram maior crescimento da área colhida e da quantidade produzida no período analisado foram Camaquã, São Jerônimo, Osório e Porto Alegre. Com relação ao rendimento médio destacaram-se as microrregiões da Campanha Central, Campanha Meridional, São Jerônimo e Campanha Ocidental.

Tabela 3 - Índices de crescimento da área colhida, quantidade produzida e rendimento médio do arroz no Rio Grande do Sul de 1991 a 2013, tendo como ano-base 1991

\begin{tabular}{l|c|c|c|c|c|c}
\hline \multirow{2}{*}{ Microrregiões } & \multicolumn{2}{c|}{ Área Colhida } & \multicolumn{2}{c}{$\begin{array}{c}\text { Quantidade } \\
\text { Produzida }\end{array}$} & \multicolumn{2}{c}{$\begin{array}{c}\text { Rendimento } \\
\text { Médio }\end{array}$} \\
& 1991 & 2012 & 1991 & 2012 & 1991 & 2012 \\
\hline 1. Cachoeira do Sul & 100 & 129,66 & 100 & 190,62 & 100 & 147,01 \\
\hline 2. Camaquã & 100 & 188,77 & 100 & 258,95 & 100 & 137,18 \\
\hline 3. Campanha Central & 100 & 130,64 & 100 & 236,36 & 100 & 180,92 \\
\hline 4. Campanha Meridional & 100 & 124,08 & 100 & 211,39 & 100 & 170,36 \\
\hline 5. Campanha Ocidental & 100 & 138,07 & 100 & 223,84 & 100 & 162,13 \\
\hline 15. Jaguarão & 100 & 112,00 & 100 & 152,47 & 100 & 136,13 \\
\hline 17. Litoral Lagunar & 100 & 82,73 & 100 & 122,62 & 100 & 148,22 \\
\hline 20. Osório & 100 & 170,26 & 100 & 261,68 & 100 & 153,70 \\
\hline 22. Pelotas & 100 & 126,50 & 100 & 193,41 & 100 & 152,89 \\
\hline 23. Porto Alegre & 100 & 166,14 & 100 & 232,73 & 100 & 140,09 \\
\hline 24. Restinga Seca & 100 & 153,60 & 100 & 208,41 & 100 & 135,68 \\
\hline 27. Santa Maria & 100 & 113,95 & 100 & 159,92 & 100 & 140,34 \\
\hline 31. São Jerônimo & 100 & 188,35 & 100 & 319,45 & 100 & 169,61 \\
\hline
\end{tabular}

Fonte: Elaborado pelas autoras. 
A Tabela 4 apresenta os valores do grau de concentração da produção de arroz, medido pelo coeficiente de Gini Locacional $(G L)$ para o mesmo período de análise considerado no cálculo do índice de especialização geográfica $Q L$. Em 1991 o $G L$ era de 0,50, reduziu para 0,49 em 2000 e para 0,44 em 2012. Os valores dos coeficientes $G L$ indicam que a concentração espacial da produção de arroz não é elevada e está reduzindo-se ao longo do tempo.

Tabela 4 - Coeficiente de Gini Locacional $(G L)$

\begin{tabular}{|c|c|c|c|}
\hline Anos & $1990 / 1991$ & 2000 & 2012 \\
GL & 0,50 & 0,49 & 0,44 \\
\hline
\end{tabular}

Os resultados deste estudo apontam para a existência de aglomerações produtivas ao identificar microrregiões especializadas na cultura do arroz. Essa informação confirma a Hipótese A, que sugere a existência das aglomerações. Os benefícios gerados pela aglomeração, que aumentou ao longo do tempo, são os apontados pela literatura. A geração de vantagens competitivas defendidas por Marshall (FOCHEZATTO, 2010), com o trabalho cooperado e com a organização de uma infraestrutura para a comercialização é verificado pela existência de entidades formadas por produtores, entidades de assistência técnica voltada ao setor (Irga), melhoramento genético de plantas e dos processos de produção e também por políticas voltadas ao desenvolvimento do setor.

O aumento das microrregiões especializadas na atividade ao longo do tempo indica uma distribuição espacial da atividade, confirmada pelo coeficiente de Gini Locacional (GL) que apresentou redução no decorrer do período analisado. A Hipótese B esperava que os resultados apontassem para uma concentração da atividade ao longo do tempo, em virtude da formação de aglomerações. A desconcentração mostra um aumento de regiões envolvidas economicamente e na produção do arroz.

Os resultados para a produção do arroz indicam aumento da aglomeração com a descentralização das atividades. Esses resultados diferem dos encontrados para a produção de leite por Marion Filho, Fagundes e 
Schumacher (2011), uma vez que estes autores verificam o aumento da especialização e também da concentração. Tais informações mostram o crescimento de aglomerações em setores produtivos diferentes no Estado, mas que apresentam diferenças nos efeitos com relação ao grau de concentração.

A identificação das aglomerações do arroz permitiu a verificação do crescimento e do desenvolvimento do setor e da região, uma vez que os resultados indicam aumento das aglomerações especializadas na atividade. A organização estratégica do setor para criar oportunidades e novos mercados de atuação por meio de programas como o Brazilian Rice, com o envolvimento de instituições e produtores, o incentivo à produção com qualidade, o apoio de órgãos técnicos e formação de entidades confirma que as aglomerações geram desenvolvimento e vantagens competitivas ao setor, argumento defendido por Schmitz e Nadvi (1999) e Monasterio e Cavalcante (2011).

\section{Considerações Finais}

Este trabalho investigou quais são as microrregiões especializadas economicamente na produção do arroz e o grau de concentração espacial da produção nos anos de 1991, 2000 e 2012. Para contribuir nesta análise partiu-se da descrição da área colhida, do rendimento médio e da quantidade produzida de arroz. Verificou-se um crescimento no período analisado, uma vez que a quantidade produzida dobrou, o aumento na área colhida foi de dois terços e no rendimento médio de um terço. Tais resultados indicam crescimento na produtividade, que podem estar associados a melhorias tecnológicas em equipamentos e insumos.

Com relação à localização das microrregiões especializadas na produção de arroz, os resultados apontam que estão localizadas nas regiões sul e litoral do Rio Grande do Sul. O Quociente Locacional indicou um crescimento no número de regiões especializadas no produto ao longo do período analisado. Algumas microrregiões especializadas aumentaram o índice de 
especialização, enquanto outras apresentaram redução. $\mathrm{O}$ aumento de microrregiões especializadas indica uma distribuição espacial, o que foi confirmado pela redução do coeficiente de Gini Locacional ao longo do tempo.

Ao investigar o grau de concentração e de especialização de regiões produtoras de arroz este estudo indicou as regiões que podem ser consideradas dependentes economicamente do produto. Além disso, mostrou a evolução da produção ao longo do tempo e o recente panorama de crescimento do setor incentivados por programas como o Brazilian Rice, que busca consolidar o produto brasileiro no mercado internacional. Estudos regionais podem auxiliar na compreensão das relações econômicas entre regiões a determinados setores ou produtos de forma a permitir, por exemplo, a elaboração de programas conjuntos para incentivar as economias locais a desenvolverem seu produto e estabelecer parcerias para comercialização.

Os métodos aplicados neste estudo podem ser empregados para diferentes produtos ou setores porque permitem a identificação de aglomerações e o grau de especialização de regiões sobre o que se pretende investigar. Conforme os trabalhos citados, existem diferentes aplicações ao setor industrial, mas também já existem aplicações a produtos agropecuários. Sugere-se, para trabalhos futuros, investigar os desafios da produção de arroz, devido ao novo cenário econômico que levou ao aumento da produção e da comercialização externa, diante do preço do produto e insumos, custos de propriedade ou arrendamento de terras e de que forma o setor pode tornar-se um exemplo de consolidação para outros setores da economia gaúcha, uma vez que os produtores têm acesso a um programa de incentivo ao setor.

\section{Referências}

ALMEIDA, T. A. Produção teórica em economia regional: das formulações clássicas aos modelos endógenos de desenvolvimento. In: SEMANA DE ECONOMIA UESB, 12, 2013, Bahia. Anais Eletrônicos... Bahia: Uesb, 2013. Disponível em: <http://www. uesb.br/eventos/semana_economia/2013/anais-2013/a04.pdf>. Acesso em: 27 out. 2015. 
AMARAL FILHO, J. A endogeneização no desenvolvimento econômico regional e local. Revista Planejamento e Políticas Públicas, n. 23, jun. 2001.

ATLAS SOCIOECONÔMICO DO RIO GRANDE DO SUL. Arroz. Disponível em: <http://www.atlassocioeconomico.rs.gov.br>. Acesso em: 3 nov. 2015.

AUDRETSCH, D.; FELDMAN, M. R\&D spillovers and the geography of innovation and production. The American Economic Review, v. 86, n. 3, jun. 1996.

BENKO, G. A ciência regional. Celta: Oieiras, 1999.

BITENCOURT, R. S.; GUIMARÃES, L. B. M. Aplicação do coeficiente de Gini Locacional e do Quociente Locacional como apoio à delimitação geográfica de sistemas locais de produção: o setor coureiro-calçadista do RS. In: ENCONTRO NACIONAL DE ENGENHARIA DA PRODUÇÃO, 32., Bento Gonçalves-RS, 15 a 18 out. 2012.

BOLSA BRASILEIRA DE MERCADORIAS (BBM). Leilões agropecuários - arroz. Disponível em: <https://www.bbmnet.com.br>. Acesso em: 14 out. 2015.

BOUDEVILLE, J. Los espacios economicos. Buenos Aires: Eudeba, 1969.

CAVALCANTE, L. R. M. T. Produção teórica em economia regional: uma proposta de sistematização. Revista Brasileira de Estudos Regionais e Urbanos, v. 2, n. 1, p. 9-32, 2008.

COMPANHIA NACIONAL DE ABASTECIMENTO (Conab). Acompanhamento da safra brasileira de grãos de 2014. Disponível em: <http://www.conab.gov.br>. Acesso em: 22 set. 2015.

CORAGGIO, J. L. Las Bases teóricas de la planificación regional en America Latina (un enfoque critico). Demografia y Economia, v. 14, n. 2, p. 141-178, 1980.

EMPRESA BRASILEIRA DE PESQUISA AGROPECUÁRIA(Embrapa). Cultivo do arroz irrigado no Brasil. Versão eletrônica, nov. 2005. Disponível em: <http:// sistemasdeproducao.cnptia.embrapa.br>. Acesso em: 22 set. 2015.

EMPRESA BRASILEIRA DE PESQUISA AGROPEGUÁRIA. Embrapa. Agência Embrapa de Informação Tecnológica: árvore do conhecimento. Versão eletrônica, fev. 2010. Disponível em: <http://www.agencia.cnptia.embrapa.br>. Acesso em: 3 nov. 2015.

FOCHEZATTO, A. Políticas de estabilização macroeconômica do plano real e seus efeitos sobre o agronegócio brasileiro. Revista de Economia e Sociologia Rural, v. 41, p. 779-802, 2004. 
FOCHEZATTO, A. Desenvolvimento regional: novas abordagens para novos paradigmas produtivos. In: CONCEIÇÃO, Octávio A. C. et al. (Org.). O ambiente regional. Porto Alegre: FEE, 2010. (Três décadas de economia gaúcha, 1).

FUNDAÇÃO DE ECONOMIA E ESTATÍSTICA DO RIO GRANDE DO SUL (FEE). FEE Dados Abertos. Disponível em: <http://www.fee.rs.gov.br/>. Acesso em: 14 out. 2015 .

HADDAD, P. R. Medidas de localização e de especialização. In: HADDAD, P. R. et al. (Org.). Economia regional: teorias e métodos de análise. Fortaleza: BNB-Etene, 1989.

HOFFMANN, R. Estatística para economistas. São Paulo: Pioneira Thomson Learning, 2001.

HOFFMANN, R. et al. Administração da empresa agrícola. São Paulo: Livraria Pioneira Editora, 1981.

INSTITUTO RIO-GRANDENSE DO ARROZ (Irga). Brazilian Rice completa dois anos de conquistas e desafios. Revista Lavoura Arrozeira, v. 62, n. 462, p. 28-33, abr./jun. 2014.

KELLER, P. F. Clusters, distritos industriais e cooperação interfirmas: uma revisão da literatura. Revista Economia e Gestão, v. 8, n. 16, p. 30-47, 2008.

KRUGMAN, P. Geography and trade. Cambridge: MIT Press, 1991.

LIPIETZ, A. O capital e seu espaço. São Paulo: Nobel, 1987.

MARION FILHO, P.; FAGUNDES, J. O.; SCHUMACHER, G. A produção de leite no Rio Grande do Sul: produtividade, especialização e concentração (1990-2009). Revista de Economia e Agronegócio, v. 9, p. 233-252, 2011.

MINISTÉRIO DA AGRICULTURA (Mapa). Vegetal-arroz. Disponível em: <http:// www.agricultura.gov.br>. Acesso em: 22 set. 2015.

MINISTÉRIO DO DESENVOLVIMENTO, INDÚSTRIA E COMÉRCIO EXTERIOR (MDIC). Comércio exterior. Disponível em: <http://www.mdic.gov.br>. Acesso em: 14 out. 2015.

MONASTERIO, L. Indicadores de análise regional e espacial. In: CRUZ, B. O. et al. (Org.). Economia regional e urbana: teorias e métodos com ênfase no Brasil. Brasília: Ipea, 2011. 
MONASTERIO, L.; CAVALCANTE, L. R. Fundamentos do Pensamento Econômico Regional. In: CRUZ, B. O. et al. (Org.). Economia regional e urbana: teorias e métodos com ênfase no Brasil. Brasília: Ipea, 2011.

OLIVEIRA, C. F.; STULP, V. J. O impacto de políticas tributárias sobre o arroz do Rio Grande do Sul no contexto do Mercosul. Revista de Economia e Sociologia Rural, v. 49, p. 647-679, 2011.

PEREIRA, J. A. Cultura do arroz no Brasil: subsídios para a sua história. Teresina, PI: Embrapa Meio-Norte, 2002.

POERSCHKE, R. P.; MORAIS, I. A. C. Determinantes da demanda brasileira por importação de arroz: uma abordagem não linear. Revista de Economia e Sociologia Rural, v. 52, p. 177-194, 2014.

PUGA, F. P. Alternativas de apoio a MPMES localizadas em arranjos produtivos locais. Textos para Discussão 99. Rio de Janeiro: BNDES, jun. 2003.

REZENDE, A. C.; DINIZ, B. P. C. Identificação de clusters industriais: uma aplicação de índices de especialização e concentração, e algumas considerações. Revista de Desenvolvimento Regional (Redes), v. 18, p. 38-54, maio/ago. 2013.

SANTOS, M. Metamorfose do espaço habitado, fundamentos teórico e metodologico da geografia. São Paulo: Hucitec, 1988.

SCHMITZ, Hubert; NADVI, Khalid. Clustering and industrialization: introduction. World Development, v. 27, n. 9, p. 1.503-1.514, 1999.

SUZIGAN, W. et al. Coeficientes de Gini Locacionais - GL: aplicação à indústria de calçados do Estado de São Paulo. Nova Economia, v. 13, p. 39-60, jul./dez. 2003. ZAMBERLAN, C. O.; SONAGLIO, C. M. A produção orizícola brasileira a partir da década de 1990: evolução e perspectivas econômicas. Qu@litas Revista Eletrônica, v. 1, p. 1-15, 2011.

Recebido em: 11/1/2016

Aceito em: 2/9/2016 